\title{
An Appraisal of Farmers Internet Use for Sourcing Agricultural Information in North- Western Nigeria.
}

\author{
Abdul-Aziz Haruna ${ }^{1, *}$ and D. Baba ${ }^{l}$ \\ ${ }^{1}$ NAERLS, Ahmadu Bello University Zaria-Nigeria
}

\begin{abstract}
This paper examined the level of farmers awareness and experiences in use of the Internet for sourcing agricultural information by farmers in the north-western Nigeria who are also privileged to have Internet services and cafes' available in their communities. The study adopted survey method using questionnaire as an instrument for data collection. The population sampled for the survey was farmers who as well leave in both semi-urban and rural areas of Kaduna and Kano State of the North West agro-ecological Zone, of Nigeria. A total of one hundred (100) farmers were randomly selected using purposive sampling technics to form the sample size. Findings revealed that farmers lack awareness for using the Internet as an alternative means of getting Agricultural Information easily even with the shortage of extension agents. The study further identifies the farmer's constraints in using the internet for information to low awareness, low access and lack skills. The study thus, recommended that agricultural agencies and other stakeholders in Nigeria should embark on advocacy and awareness campaign to farmer's cooperative societies/groups on the uses of Internet for sourcing agricultural information.
\end{abstract}

\section{Introduction}

Agricultural development is vital for national transformation and increased of food security and to achieve this, farmers, researchers/scientist, and extension workers need to be well informed. In view of Jensen [5], the right information will guarantee knowledgeable, active, engaged and informed farmers who can participate wisely in the country's economic production and consequently development.

Radio, Television, Community newspapers and extension workers have been identified as various sources of agricultural information to farmers. However this paper looks at the introduction of the internet services to harness communication and information need for agricultural development purposes. The medium is a relatively new channel of disseminating mass mediated information. Adeyanju and Mbibi [1] are of the view that farmers should be aware and knowledgeable of ICTs significant role and utilize it effectively in obtaining their information needs. This is important considering the

\footnotetext{
* Corresponding author: abdulharunas@yahoo.com
} 
successful employment of ICTs in Agricultural production across the world. Okunola [2] posits that in the $21^{\text {st }}$ century, information dissemination and retrieval depend largely on the ability of one to access and utilize the internet effectively through the use of various technological means. Various researchers/scientists state that there have been efforts to harness communication and information media for planned developments purposes. This is in recognition of the function which information and communication media can take part in in fostering and mobilizing people towards national development. The world has become a global village as predicted by Mcluhan [8], with its rapid transformation and increased knowledge transfer.

\section{The Internet Services}

According to food and Agriculture Organisation FAO [4], the Internet was developed in the early 1960's it was then intended as a decentralized computer system that was less susceptible to nuclear attack than a centrally strained system, a devised whereby computers sent packets of information from one computer to another across the United States. Today, Internet connects researchers located at various Universities and colleges, individuals, organizations, continents and the world at large. Various studies revealed the potential of internet to all aspect of human development. Similarly, the internet service has turn out to be a vast and growing global network system that people use to converse, debate, meet, teach, learn, buy and sell, and virtually every kind of information including agriculture. Internet use is not merely limited to shopping and contact with people, but it also provides the atmosphere for news sharing and endorse the people to be resourceful with the latest news. We can access the data easily wherever it may be across the world. Internet is also a very good form of communication for people who want to express their own view points and feelings. For youth, internet is not merely an avenue of knowledge but also provide an entertainment aspect such as online games, downloading movies, music, charts etc. But this is not the only basis the internet appeals to the younger age group. They also established that the internet provides ease to explore and transmit research result to the end-users.

Agricultural Research Institutes in Nigeria are facing challenges in the area of extension communication delivery due to a number of reasons among which is shortage of extension workers in Nigeria. Extension workers are agents for communicating new agricultural innovation to farmers. The current extension/farmer ratio according National Agricultural Extension and Research Liaison Services "NAERLS [7]" Agricultural Performers Survey (APS) report stood at 1: 3500 farm families, even with these the institutes are essential to respond efficiently to the demands of policy makers, private sector investors and donor agencies, farmers and other stakeholders in the agricultural business. They are being asked to convey research outputs that will improve agricultural productivity, food security, in order to increase their countries competitiveness in global markets, and contribute to sustainable development. Therefore, this calls for need of agricultural research institutes to prioritize and strategize their responses in-terms of agricultural extension services.

As such, the internet offers opportunities for collaborative and parallel communication and opening up new, non traditional communication channels for rural communities and development organizations. Most notably, it can sustain button-up enunciation of development needs and perceptions, food and Agriculture Organization FAO [4] Going by the shortage of extension agents who facilitates adoption of new farming innovations in Nigeria, it is therefore paramount for all agricultural stakeholders most especially farmers to effectively utilize the potential of Internet to enhance their activities in terms of information and communication dissemination. Therefore the objectives of this study are:-

1. To identified the extent of farmers experience and skills in the use of Internet for Agricultural information. 
2. To examine the relationship between farmers Age, level of education and level of internet awareness as a source of agricultural information.

3. To assess farmer's constraints in use of Internet for obtaining agricultural information.

\section{Methodology}

The study adopts survey method using questionnaire as an apparatus for data gathering. The population sampled for the survey was farmers who as well leave in both semi-urban and rural areas of Kaduna and Kano State of the North West agro-ecological Zone, of Nigeria. The choice of the zone was because farming is the major activity of the people in the zone and represent major food supplier in Nigeria, it is characterised by mixed cropping farming and livestock production for meat. It has a very few large and medium scale farmers that are engage into mechanised farming with majority smallholder farmers. A total of one hundred (100) farmers were randomly selected using purposive sampling technics to form the sample size. Descriptive statistics using table and chart was used to present the result while, regression analysis was used to determine the relationship between Dependent variables ie Internet skill, level of Internet awareness with Independent variables such as age, level of education, years of farming experience, Internet access, using internet to source information. Ordinary regression is a popular tool in analyzing relationship between dependent and independent variable it provides best explanation on existence, strength, magnitude, significance as well as form of relationship in a model Gujarati [3].

\section{Result Presentations}

The presentation and analysis of data generated for this study are presented below in tables and charts. The result in the tables indicates measurement of association between the dependent and the independent variables in other to find out the relationship between the variables using regression;

Table 1. Relationship between farmers Internet skill, Level of Internet awareness with * Age

\begin{tabular}{|l|c|c|c|c|c|c|}
\hline Measures of Relationship & $\mathbf{R}$ & R Squared & Eta & Eta Squared & F & Sig. \\
\hline $\begin{array}{l}\text { Assessing farmers Internet } \\
\text { skill * Age }\end{array}$ & -.192 & .037 & .499 & .249 & 3.519 & .065 \\
\hline $\begin{array}{l}\text { Level of Internet awareness } \\
* \text { Age }\end{array}$ & -.129 & .017 & .555 & .308 & 1.722 & .194 \\
\hline
\end{tabular}

$* \mathrm{P}<0.05$

The result in Table 1 shows that farmer's age has no any significance to the farmer's level of internet awareness and skills. This means that farmer's age those not matter when using the internet to source for agricultural information, in other words, internet usage cut across all ages whether young or old can utilized its benefit for self development.

Table 2. Relationship between farmers Internet skill, Level of Internet awareness with * Years of Farming Experience

\begin{tabular}{|l|c|c|c|c|c|c|}
\hline Measures of Relationship & $\mathbf{R}$ & $\begin{array}{c}\mathbf{R} \\
\text { Squared }\end{array}$ & Eta & $\begin{array}{c}\text { Eta } \\
\text { Squared }\end{array}$ & F & Sig. \\
\hline $\begin{array}{l}\text { Assessing farmers Internet skill * Years of } \\
\text { Farming Experience }\end{array}$ & -.111 & .012 & .576 & .332 & 1.493 & .225 \\
\hline $\begin{array}{l}\text { Level of Internet awareness * Years of } \\
\text { Farming Experience }\end{array}$ & -.017 & .000 & .512 & .262 & .032 & .859 \\
\hline
\end{tabular}


${ }^{*} \mathrm{p}<0.05$

Result in table 2 also reveals that farmers years of farming experience has no significant difference in terms of farmer's internet skills and awareness which means that years of farming experience those not matter too, any farmer can utilized the potential of internet as agricultural information data base even without the assistance of an extension agents. This result further reveals that the internet can harness the activity of extension agents if utilized.

Table 3. Relationship between farmers Internet skill, Level of Internet awareness * Educational level

\begin{tabular}{|l|c|c|c|c|c|c|}
\hline $\begin{array}{l}\text { Measures of Relationship } \\
\text { Assessing farmers Internet skill }\end{array}$ & $\mathbf{R}$ & $\begin{array}{c}\mathbf{R} \\
\text { Squared }\end{array}$ & Eta & $\begin{array}{c}\text { Eta } \\
\text { Squared }\end{array}$ & F & Sig. \\
\hline $\begin{array}{l}\text { Educational level } \\
\text { Level of Internet awareness } \\
\text { Educational level }\end{array}$ & $*$ & .503 & .822 & .676 & 148.972 & .000 \\
\hline
\end{tabular}

$* \mathrm{p}<0.05$

Table 3 shows that farmer's educational level has a 1\% significant level also farmer's internet skill and awareness. This means that respondent's educational background has a relationship and significant role in farmer's internet skills and awareness of the internet to source for agricultural information.

Table 4. Relationship between farmers Internet skill, Level of Internet awareness * Farmers Access to Internet

\begin{tabular}{|l|l|l|l|l|l|l|}
\hline \multicolumn{1}{|c|}{ Measures of Relationship } & R & $\begin{array}{c}\text { R } \\
\text { Squared }\end{array}$ & Eta & $\begin{array}{c}\text { Eta } \\
\text { Squared }\end{array}$ & F & Sig. \\
\hline $\begin{array}{l}\text { Assessing farmers Internet skill * } \\
\text { Farmers Access to Internet }\end{array}$ & -.111 & .012 & .854 & .730 & 4.395 & .039 \\
\hline $\begin{array}{l}\text { Level of Internet awareness * Farmers } \\
\text { Access to Internet }\end{array}$ & -.201 & .040 & .551 & .303 & 5.553 & .020 \\
\hline
\end{tabular}

$* \mathbf{P}<\mathbf{0 . 0 5}$

Result in table 4 indicates 5\% significance level, this shows that relationship exist between farmers internet skill, level of awareness and farmers access to internet, which means that farmers in the study area might have availability of internet services but could not utilized it to source for agricultural information despites the high rate of extension/farmer ratio in the study area.

Table 5: Assessing farmers Internet skill, Level of Internet awareness * Ever use the Internet to source Information

\begin{tabular}{|l|c|l|l|l|l|l|}
\hline \multicolumn{1}{|c|}{ Measures of Relationship } & $\mathbf{R}$ & $\begin{array}{c}\mathbf{R} \\
\text { Squared }\end{array}$ & Eta & $\begin{array}{c}\text { Eta } \\
\text { Squared }\end{array}$ & F & Sig. \\
\hline $\begin{array}{l}\text { Assessing farmers Internet skill * Ever } \\
\text { use the Internet to source Information }\end{array}$ & .115 & .013 & .815 & .665 & 3.794 & .054 \\
\hline $\begin{array}{l}\text { Level of Internet awareness * Ever use } \\
\text { the Internet to source Information }\end{array}$ & -.076 & .006 & .388 & .151 & .650 & .422 \\
\hline
\end{tabular}

*P $<0.05$ 
Table 5 shows a significant relationship at 10\% between internet skills and ever use the internet to source for agricultural information. This means that using the Internet to source for agricultural information requires some skills. However, there is no significant relationship between farmers level of internet awareness and ever uses the internet to source for agricultural information.

Table 6. Assessing farmers Internet skill, Level of Internet awareness * Internet as alternative source of agricultural information

\begin{tabular}{|l|l|l|l|l|l|l|}
\hline Measures of Relationship & $\mathbf{R}$ & $\begin{array}{l}\text { R } \\
\text { Squared }\end{array}$ & Eta & $\begin{array}{l}\text { Eta } \\
\text { Squared }\end{array}$ & F & Sig. \\
\hline $\begin{array}{l}\text { Assessing farmers Internet skill * } \\
\text { Internet as alternative source of } \\
\text { agricultural information }\end{array}$ & -.102 & .010 & .668 & .446 & 1.787 & .184 \\
\hline $\begin{array}{l}\text { Level of Internet awareness * Internet as } \\
\text { alternative source of agricultural } \\
\text { information }\end{array}$ & .241 & .058 & .839 & .704 & 18.841 & .000 \\
\hline
\end{tabular}

* $\mathbf{P}<0.05$

The result in table 6 shows a 1\% significant level of relationship between farmer's level of internet awareness, and with Internet as alternative source of information aside other sources. However, there is no relationship between farmer's internet skills and agreeing with internet as alternative source of information aside other sources. This means farmers needs to required internet skills for them to be capable to use the internet to source for information, similarly, the result further revealed that with good awareness farmers can adopt the use of internet as alternative source of information rather than relying on extension agents alone.

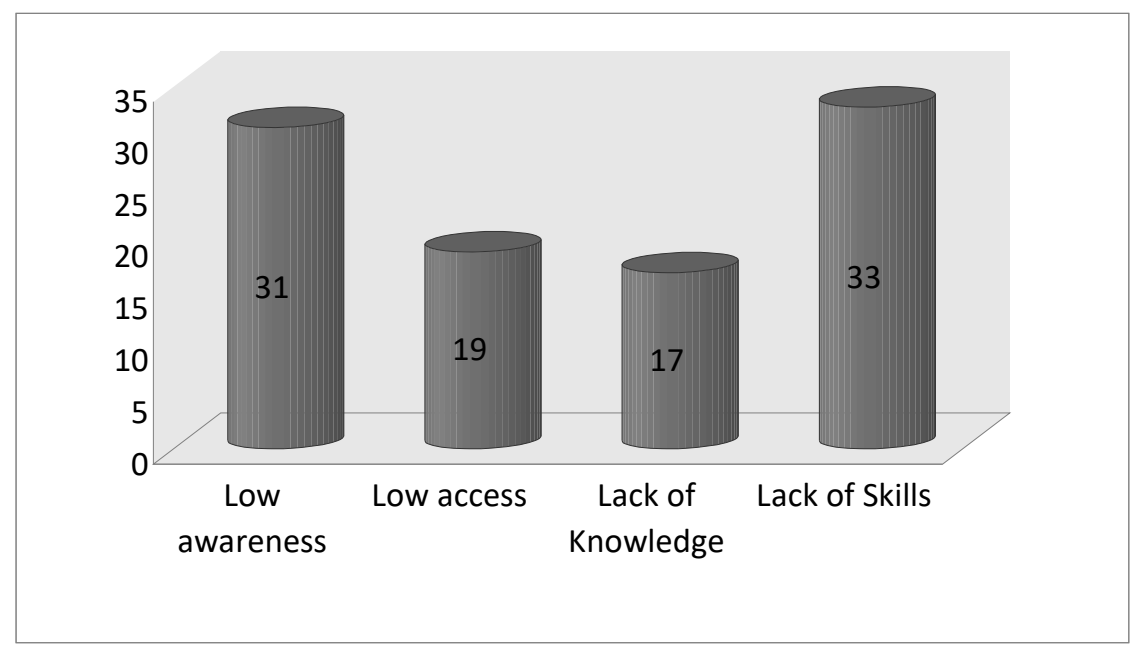

Fig. 1. Farmers constraints in using the Internet

Figure 1, identifies the farmers constraints on the use of Internet range from; low awareness, low internet access, lack of knowledge and skills to use the Internet. 


\section{Conclusions and Recommendations}

The appraisal of farmers in internet use for sourcing agricultural information in the northwest Nigeria shows that the farmers lack awareness of using the Internet for sourcing agricultural information even with the shortage of extension agents whose duty is to facilitate adoption of new farming innovations. The study also shows that with proper awareness farmers could use the Internet as another source of agricultural information looking at the opportunities provides by the Internet if properly utilize. Michiels \& Crowder [8] states that the introduction of ICT projects desires to be accompanied by support so that communities are conscious of the purposes and people have a clear considerate of their roles, and in particular how they will be element of decision making about objects, applications, content, etc. Extension agents can support and advocate for rural stakeholder participation in ICT project planning, implementation and evaluation. It was also discovered that low awareness, low access and lack of skills forms the constraints to internet usage by farmers in the area. According to Christian in web2for dev [9] the participatory network has open innovative conduct of interacting on the Internet, but certain constraints are identified: access, Cost, Time, Literacy and a certain level of media literacy. Particularly in developing countries, few people have Internet access or the means (literacy and media competence) to engage in such a conversation. Also just a few languages dominate and there are very few bridges between them. The majorities of online development debates are in English and exclude many groups from participating, a little of these constraints still remain or might even deepen web2forDev summary report [9]. Consequent to the conclusion of this study it is therefore recommended that:-

- The need for community enrollment mainly by NGOs or Public-PrivateCommunity partnership for the need of using the Internet to source for agricultural information.

- In Nigeria agricultural extension information and knowledge services are usually from government and public sector organizations such like the National Agricultural Extension and Research Liaison Services (NAERLS), with other Agricultural Research Institute (NARls) in Nigeria, to create awareness on the importance of using the internet as alternative source for Agricultural Information and to access their activities easily.

- The Nigerian government to address the problem of using Internet in agricultural and rural development via focusing on providing broadband connectivity and a content centric development approach particularly in the rural areas.

\section{References}

1. A.M. Adeyanju, J. Mbibi, "Knowledge, Awareness and Attitude of farming communities towards the use of ICT's for Rural Development". NJC. 5, 99 (2007)

2. A. Okunula EJSS. 11 (2) (2014).

3. D.N. Gujarati, Basic Econometrics: Special Indian Edition, (Fourth Edition), Tata McGraw Hill (New Delhi, India). 56-62 (2007).

4. FAO. The potentials of micro-computers in support of Agricultural Extension, education and training Rome: FAO. (1998)

5. J. Jensen. Journalism's Identity Crisis: What is the News for, www.reasononline.com (2003). 
6. M. Mcluhan, The Gutenberg Galaxy: The making of Typograhic Man. Toronto: University of Toronto Press. Retrieved on 08/08/2011 from http://www.uky.edu/ drlane/capstone/mass/determinism.htm (1962).

7. NAERLS. Agricultural performance survey. Zaria: NAERLS press. (2011)

8. S. Michiels, L. Van crowder, Discovering the magic box. Local appropriation of information \& communication technologies (ICTs).FAO, Rome. accessed: http://www.fao.org/sd/2001/KN0602a_en.htm (2001)

9. Web2 for Dev summary report, exploring the potentials of blogging for development. Htpp://natawilage.typepad: retrieved http://blogweb2fordev.net September, 2010. 